\title{
A Knowledge-Based Risk Management for the Utility Business Service Model
}

\author{
Christina Silveira \\ University of Surrey, New Malden, UK \\ christina silveira@de-gois.com
}

\begin{abstract}
The digital economy needs new indicators for emergent technologies, and to establish them, a risk analysis model is deployed as an Information System Meta research method. The role of the Utility Business Service Model (UBSM) in mitigating information technology and information systems (IT/IS) risks in the business activity: assisting to understand how the virtual enterprise paradigm is shifting established values across the IT/IS value chain. The technical infrastructure for e-commerce and ebusiness share similar risks. The PMBook (Project Management Institute) risk analysis model is used to understand the risks involved in the adoption of UBSM by potential customers.

This preliminary model will be part of a virtuous cycle of learning and informing. The twofold purpose of the knowledge-base risk management framework is (1) to summarise and categorise initial research finds about the use of the UBSM, and (2) survey the pace of adoption and acceptance of the UBSM as a service provision business model, which includes the application services provision (ASP) business model.
\end{abstract}

Keywords: Outsourcing, Utility Model, ASP business model, risk analysis, strategic, operational, knowledge, financial

\section{Introduction}

The emergence of the service provision business model has brought huge expectations of change within the outsourcing arena. Given the newness of the technological framework, it has been defined as 3rd wave outsourcing (Currie 2000). In its simplest form, the service provision business model can be defined as 'a third-party service firm, which deploys, manages and remotely hosts a pre-packed software application through centrally located servers in a "rental" or lease arrangement (CherryTree\&Co 1999). The market has also experienced many service providers folding due to factors such as bankruptcy or simple lack of customer base. To date, the service provision business model has failed to fulfil predictions for success in terms of market growth as antic ipated.

This paper is part of a wider study being carried out by the author as part of a research programme on electronic business models specialised on IT and IS infrastructure. It also draws some knowledge and information from the ALTERNATIVE project (ALTERNATIVE 2001) that has as objective to "provide

Material published as part of these proceedings, either on-line or in print, is copyrighted by Informing Science. Permission to make digital or paper copy of part or all of these works for personal or classroom use is granted without fee provided that the copies are not made or distributed for profit or commercial advantage AND that copies 1) bear this notic e in full and 2) give the full citation on the first page. It is permissible to abstract these works so long as credit is given. To copy in all other cases or to republish or to post on a server or to redistribute to lists requires specific permission from the publisher at Publisher@InformingScience.org
European SMEs with a web-enabled tool to manage risk assessment with respect to the deployment, hosting and integration of business-critical information systems by application service providers".

It focuses on the risks of using the service provision business model and in particular, the risks from a customer perspective, and it is subdivided 
into four sections. The first section introduces the context in which the risk management framework is deployed as a meta-method for analysing the service provision business model. The second section, describes the empiric conversion of the risk management approach to the research methodology. The third section describes the main findings and describes the generic risks identified as associated to service provision business model. The fourth section, establishes the broad direction for the research, which remains based on the chosen meta-method and risk management framework. This paper concludes for the service provision business model to succeed it is necessary to overcome a series of technological and businesses challenges.

\section{A Generic Definition of Utility Business Service Provision}

The model for service provisioning to business is an evolutionary change of the application service provision (ASP) model. Based on the broadest definition of ASP as provided by the ASP Consortium (ASPConsortium 2002): "Application Service Providers deliver and manage applications and computer services from remote data centres to multiple users via the Internet or private network".

An enlarged definition describes an ASP as an enterprise that maintain an infrastructure that allows the delivers via private or public network of a set or specific functional services to multiple organisations into a contracted service standard for agreed fees. The utility business service model is classified as a sub-sector of the business consultancy in IT/IS outsourcing marketplace.

This is confirmed by Currie (2000) who defines ASP as a third wave of outsourcing and "a new form of application outsourcing with the ability to manage and deliver application capabilities to multiple entities from data centres across a wide are network" (Figure 1). Any definition of business models should

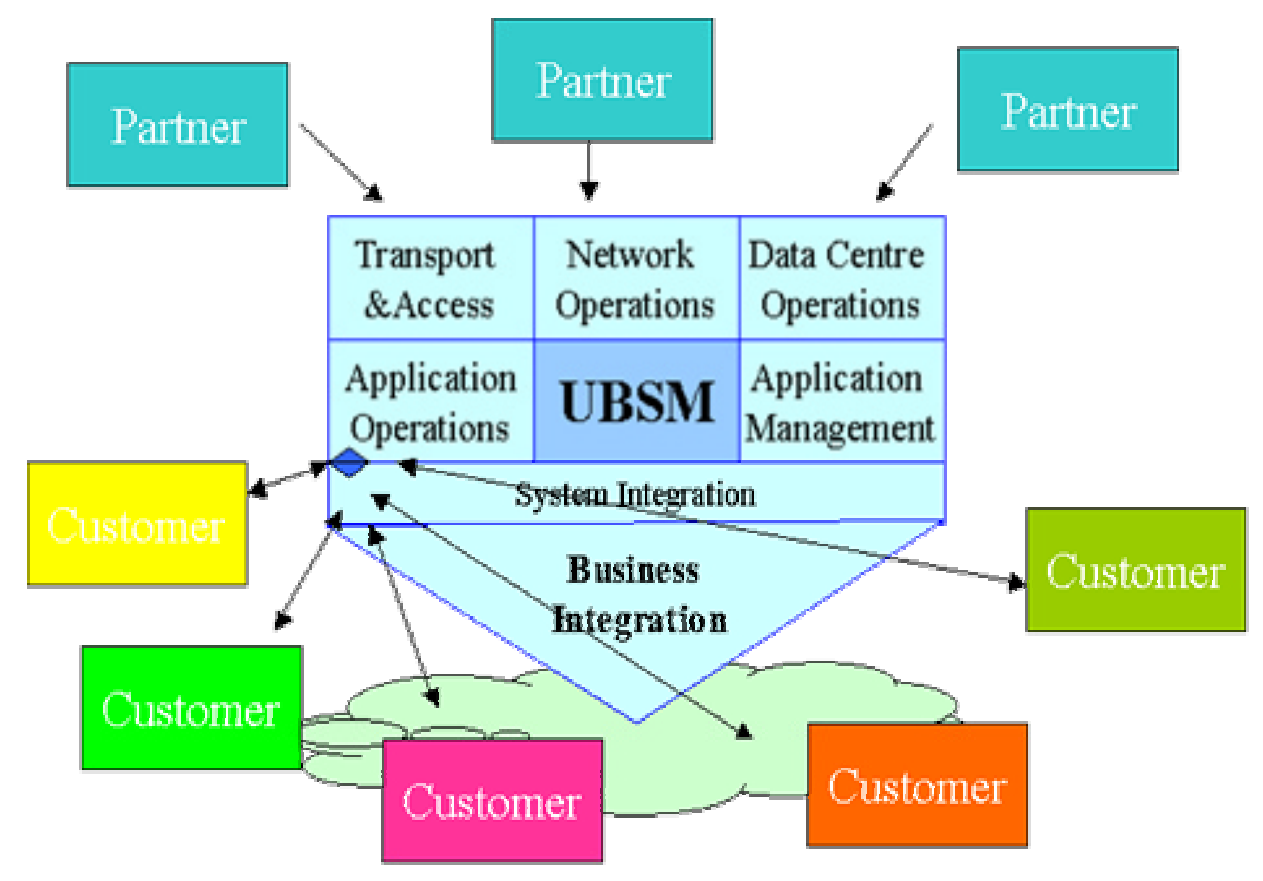

The value proposition of the Uhily Business Service model(UBSM: one-to-many comminication, hordwore and sof hare as a service

Figure 1: Basic Utility Business Service Model 
be complemented by its potential benefits to customers, of which the key benefits of service provisioning models are:

- Users can concentrate on core competencies

- Maximise IT/IS and business integration

- Control costs of all or selected IT/IS infrastructure components

- Contributes to the control of budget and cash flow

- Use new business applications faster to increase responsiveness

- Utilise latest supported enterprise, e-business, office productivity and messaging software

Although the definition above synthesizes the concept of application centred of the UBSM, the factual typology incorporates a wide range of service provision (Seltsikas and Currie 2001). However, for practical reasons, it is outside of the scope of this paper to review them in any detail.

\section{Risk Management Framework Development}

Project success, is to a degree, dependent upon on risk management and gathering of data in relation to the project risks as well as defining characteristics of such risks. Risk analysis is a vital step for identifying risks, planning for contingencies and to establish any counter-measures required. When investigating the project requirements, it is feasible to define and map the business environment of the subject

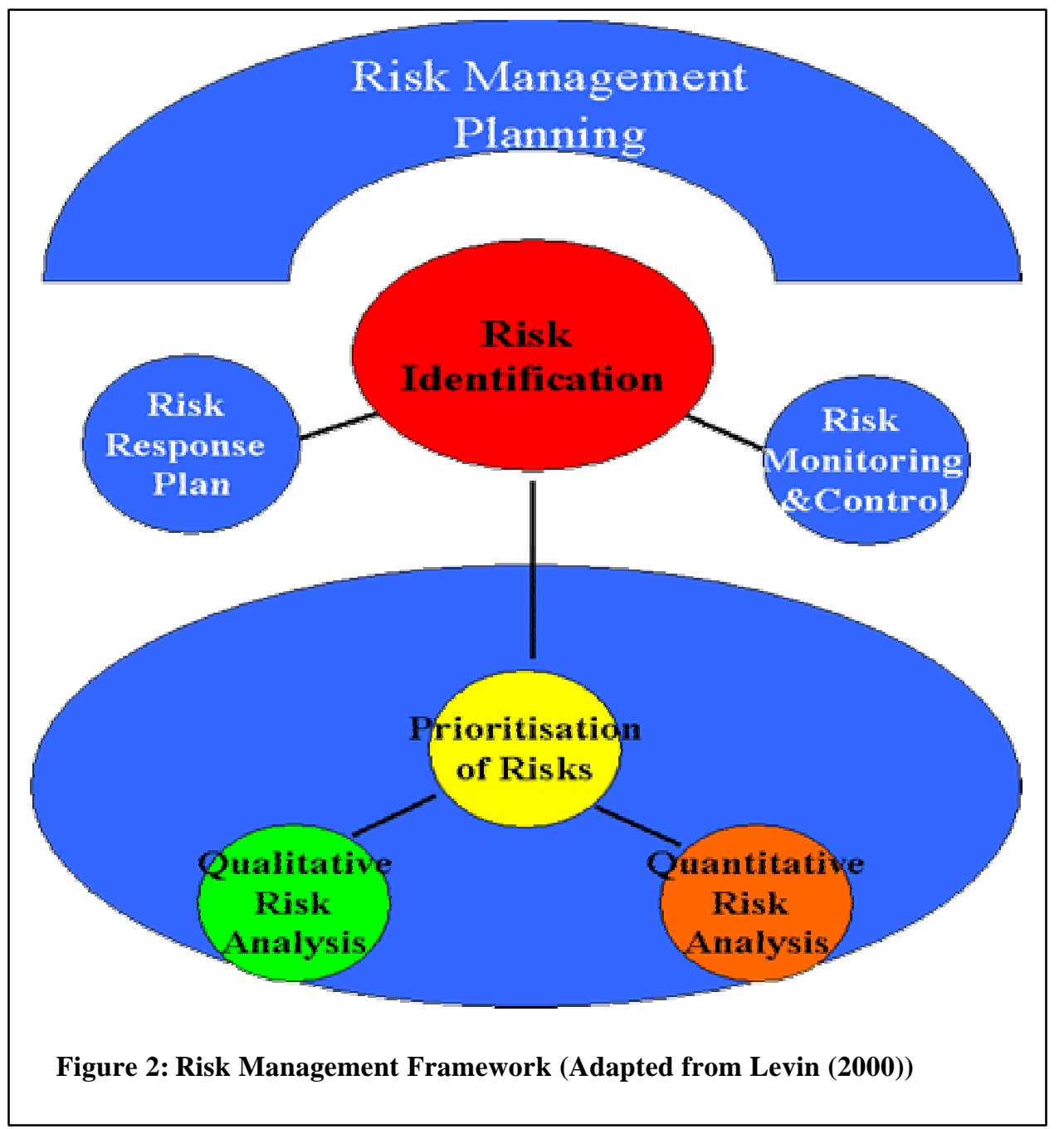


for proposed change. In general, business changes present subtle risks and potential opportunities, which may only, became clear after a detailed risk investigation has taken place.

In order to understand the risks associated to the service provision model, a risk management technique were applied, following the Project Management Institute (PMI) guidelines, which are concise, well know, almost universally applied to projects and it offers a choice of qualitative and quantitative risk analysis methods (Figure 2).

The framework was used as basis from which to begin the risk assessment and how to approach projects using the utility business service model. A set of risks is identified, classified in certain categories in terms of their impact over the project objectives. Risks are analysed from a qualitative or quantitative perspective to determine or estimate their impact on project objectives from which a risk response plan can be drawn to determine how to enhance opportunities and minimise threats. This paper does not attempt to look critically at the framework deployed, although the author recognises the pivotal role of research method selection.

\section{Research Approach}

This study took place within the context of the ALTERNATIVE project which has as primary objective to identify and to understand the issues that will facilitate the use of ASP services in European organisations and this involved research of wide spectrum covering business and market readiness to technological infrastructure, demanding the mixing of different data collection strategies as encouraged by best practices in research (Avison and Fitzgerald 1991, Denzin 1978). The overall research has been divided into four phases combining a study of the literature with market research; surveys and case study based investigative work, thus representing a coherent research strategy to investigate a practical and broad concept such as ASP.

The research concentrates on two broad categories of risks associated with the ASP business model: (a) intrinsic risks to the business market place (b) risks originated inside the organisation. Given the purpose of the research, it was deemed necessary, to analyse the generic application and service business model and to hypothesise about a suitable response plan for associated risks. This then, can be contrasted and compared against results of continuous research in the form of surveys, case studies and interviews to service provider, customer and potential customers.

The first phase of risk assessment includes the identification of the high level 'Risk Factor'. This identifies key categories of risks that may affect the project: Contractual and Tactical, Economic, Information and Service \& Delivery.

Although the scope of the research is academic, the techniques employed for information gathering were market based. This paper reports the results of surveys carried by third-parties in the area of service provision and e-business, in order to landscape how far the utility model has evolved and to build up its knowledge-based for risk management.

\section{Current Research Outcomes}

The main results and outcomes of the research formed the scope and requirement elicitation to build up a knowledge-base for risk management for the deployment of the utility business service model. They are:

- Understanding of the utility business service model and its value chain as constituent part of the ebusiness model

- Understanding of the legal and commercial issues surrounding the utility business service model 
- Identification of enabling or hindering factors for the adoption and acceptance of the utility business service model.

The Computing Services and Software Association (CSSA 2001) carried out a survey on the growth of application service provision aiming to obtain the perceptions and intentions for ASP from CEO and Senior Management. This survey included 200 Senior Managers from SMEs from the United Kingdom private sector, where $66 \%$ were responsible from IT in their organizations and $14 \%$ were in General and Finance management. Amongst the results, the analysis showed that at Senior Management there was a high awareness of the conceptual benefits of service provisioning model although just few enterprises had developed a strategy for ASP. Furthermore, a majority did not believe that web based services would significantly impact the way they will do business in the next two years. (See Figure 3.)

The data of both surveys, have been revised along with another study carried by the Federation of Electronic Industry and Department of Trade and Industry (FEI, DTI, Afdec and SBA 2002) on drivers and inhibitors for the adoption of e-commerce.

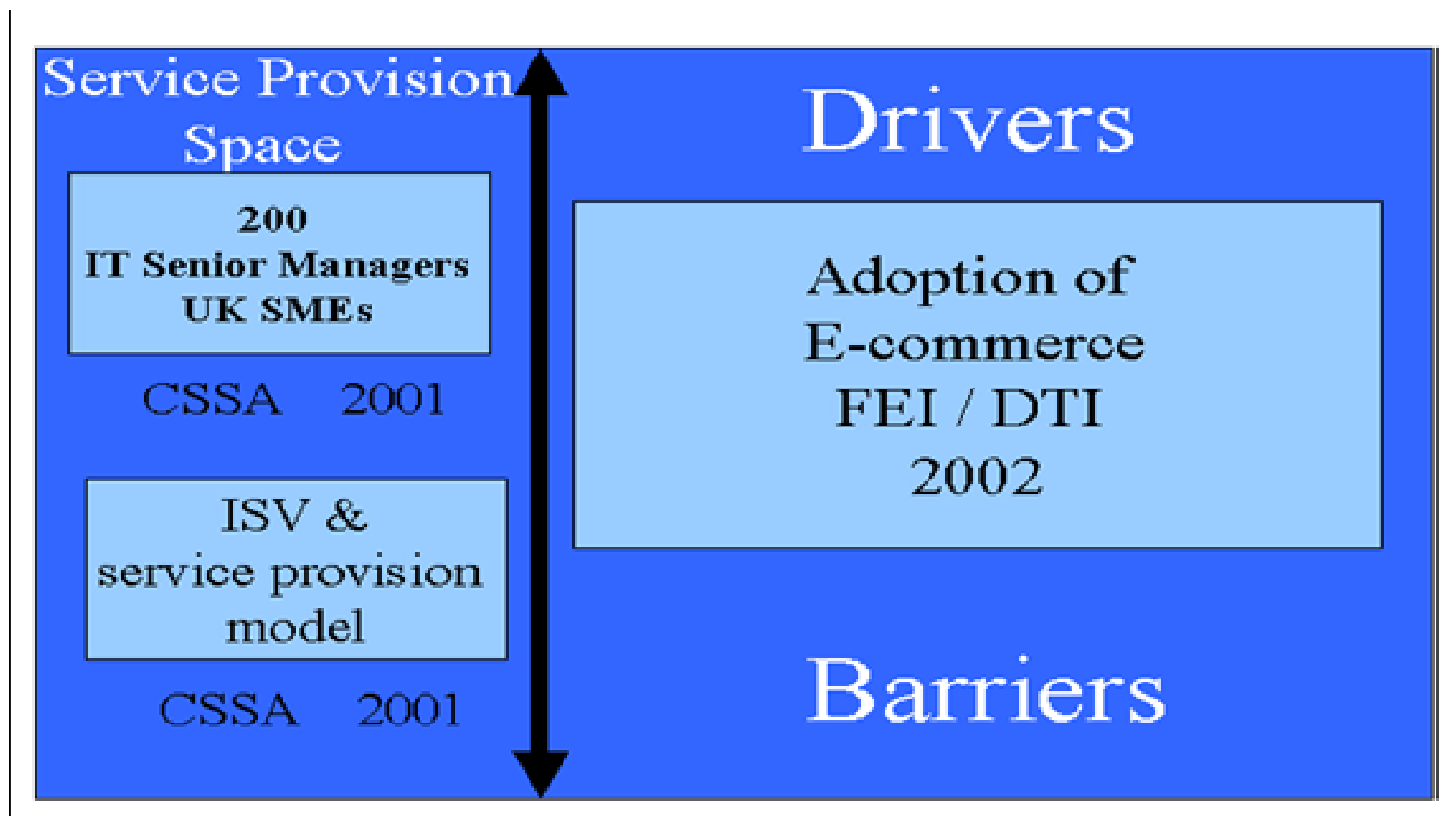

Figure3: Surveys on ASP growth (2001) and e-technology adoption

The CSSA survey measured [1] the level of interest on the application service provision model of respondent organizations and [2] the opportunities for the independent software vendors (ISV.

Interestingly, the level of interest of organizations on the service provision model was higher than the level of selling activity from providers. The survey outcome shows that there is strategic level support for the concept, and for almost half of the cases, the interest was already translated into strategy with plans to use the service provision model in the next two years. Yet, only few of those companies reported being approached by vendors. The CSSA survey respondents could not "recall the names of individual ASP", "an indicative of the lack of effective marketing to the sector". Providers stated that the lack of competition on the sector resulted in a lack of information about ASP circulating amongst potential client. Service provision firms had to choose between investing in the marketing or in research and development to improve the capabilities of the technology.

IT Senior Managers despite being aware of the concept (73\%), most of respondents did not completely understood the model. Confirming the notion that "the ASP proposition has not been successfully pro- 


\section{A Knowledge-Based Risk Management}

moted into the United Kingdom. Respondents see no value in using ASP principally because they could not see the relevance to their situation" (CSSA 2001).

Not surprisingly, amongst the types of applications being considered by these companies were those applications related to e-commerce, online payment and e-business. IT Senior Manages were satisfied with " the management of procurement and management process" of the IT and IS products (CSSA 2001). This is in line with the industry activity on the middle of 2001. Organizations were moving up their e-strategy from intranets to extranets and e-commerce and e-procurement started to be explored at strategic level. Nevertheless, despite the interest, strategic purpose and confidence on the ASP model in terms reliability and delivery, majority of these organisations expressed concern about loosing control over core applications to an ASP vendor.

At operational level more than half of respondents were positive about the fact that the ASP lowers the total cost of application provision; for almost half percent of respondents the rate of business growth and adaptability is constrained by IT, therefore improvement in security, scalability, flexibility, speed to market of IT services should improve business growth. The results of the survey conveyed the perception that legal contracts and service level agreements would assist to improve the level of IT/IS services to the business.

The survey indicated respondents believed that ASP based systems can bridge the gap between bus iness and IT systems provision. The scalability of ASP based solutions appeared to count for little; with existing systems being viewed as flexible enough to cope. Not surprisingly, more than three-quarters of those surveyed thought that cheap broadband bandwidth would promote the take-up of ASPs.

In summary, despite covering slightly different groups, both surveys found that there were concerns of loss of control, threats to data security and poor performance that could hinder the ASP market growth. Business benefits appear limited, with the costs of IT provision being re-shaped rather than released. But it was believed that ASP based services will allow SMEs' to compete effectively with large organisations.

These issues are a part of sub-sets of issues addressed by the knowledge-based risk management framework modelled by this research, which is discussed at next section.

\section{The Knowledge-Based Risk Management Framework}

The knowledge-base framework (Figure 3.1) is based on the model of Niwa (1992) and the Risk Universe Framework of Ernst \&Young (2001). The purpose of the procedure "is to facilitate the calculation of risks and improved management responses in the execution of projects commanding more comprehensive data" (Wideman 1992). It provides the ability to qualitatively analyse the sources of risk base on several factors. Within this research, each of the factors is subdivided further, to provide an analysis of the likelihood of "generic" and "qualitative" risks occurring. The risk likelihood is determined and associated to the risk impact over the business, which is then analysed and correlated with a risk level. For each risk, opportunities to gain advantage are identified, along with the potential control that the client organisation can exert over the risk situation. These results in the formation of a net risk applied to the overall project.

For the purpose of the utility business service ecosystem, the following high level categories were chosen (Ernst\&Young 2001, Wideman 1992):

[a] Tactical and Contractual risk analysis of the market structure, segment and competition; investigating local and global competition and the economics and transactions of the providers. The analysis focused on the nature and structure of key stakeholders alliances, strategic aspects of the governance of their formal and informal partnership: ethics, strategic planning, resource allocation, corporate monitor- 


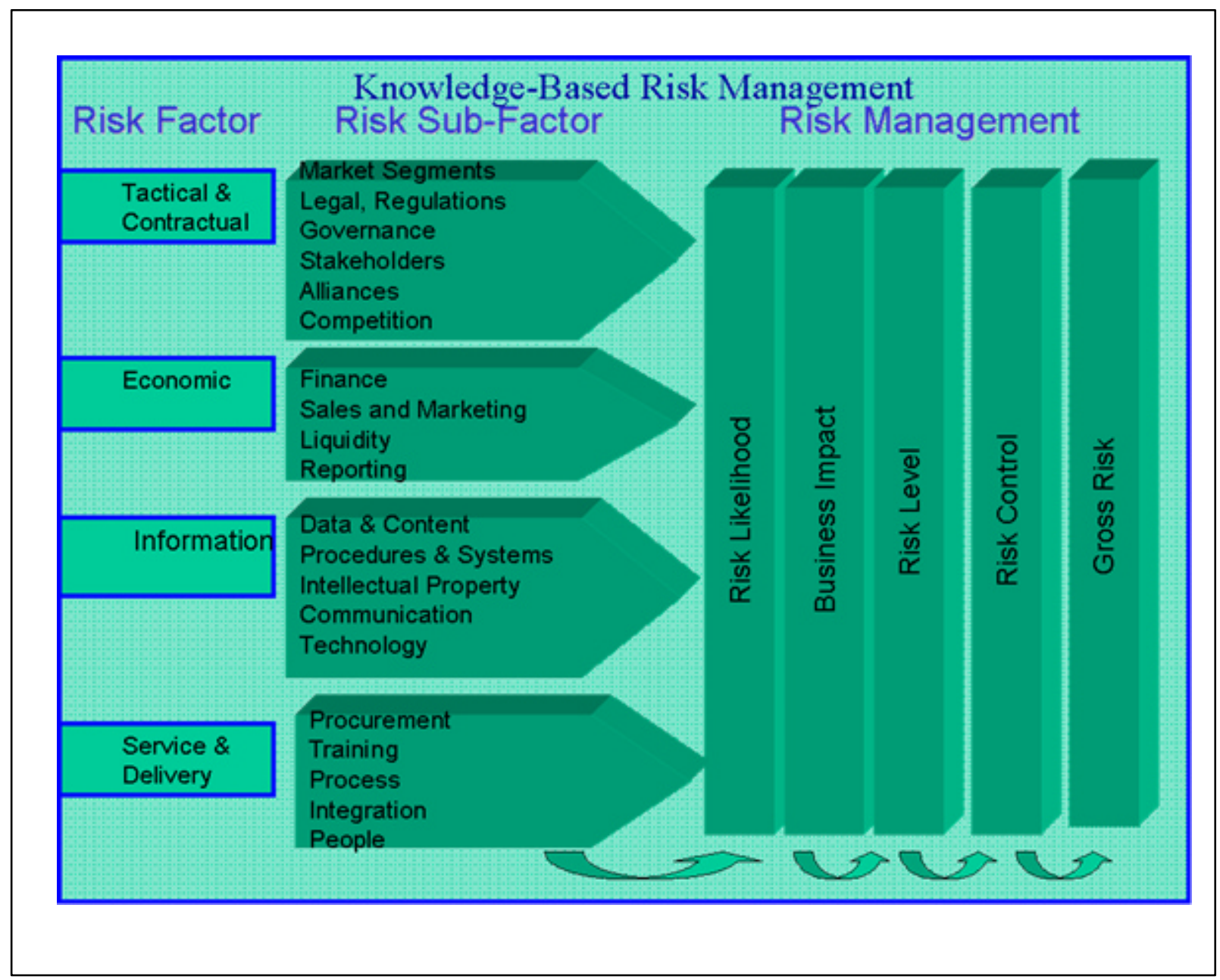

Figure 3.1: $\quad$ Knowledge-Based Risk Management Schematic based Kiyoshi Niwa model (1989)

ing and reputation. Legal aspects of the relationship would include but limited to legislative and regulatory framework, contract, and liability.

There are potential risks for client organizations, when they engage in long-term contracts with an ASP organization, especially if the ASP technology and infrastructure remains static over time. An ASP who does not innovate to improve its service, cannot reasonably offer the degree of scalability required by some customers and thus cannot seek to maintain competitive advantage. Competitors will benefit from deploying more advanced technology, enabling them to innovate and to obtain further competitive standing. To mitigate that risk, the agreement should contain a contractual claim for technology deve lopment and innovation in par with latest development of the market place. Kern, Willcoks and Lacity (2002), are more radical and recommend short term contracts to avoid to be tied up to "immature suppliers". Although the ASP market is driven by technology, it is not growing as rapidly. Not many ASPs are in essence technologically superior, and thus making ASP service offerings to customers, evenly available. For example, organizations such as Microsoft, aim to remain neutral and not favour any particular vendor and offer the same level of support to all ASP hosting Microsoft products.

Globalisation and the universal presence of the Internet will require the ASP to embrace the language requirement of customers. Software applications may have to be customised to accommodate language differences of geographically dispersed clients. This is further extended to the services offered by the service provider such as the Help-Desk. Upgrading local applications to provide a global service can 
increase the operational cost of the ASP, which in turn can be potentially filtered on to the customer. Increased customer service costs disturb the basic "one-to-many" leverage that ASP needs to succeed in the long term. The location of data centres is also an important factor to assess. The ASP data centres may be located at different countries to the organisation. In many instances the customer may not be aware of this for numerous reasons, including security. Kern, Willcoks et al. (2002) recommends "careful consideration of current and future bus iness, economic, and technical factors" for the business areas affected by the ASP offering.

"For buyers, it is not enough to know what they need to purchase-organizations must have a proc-

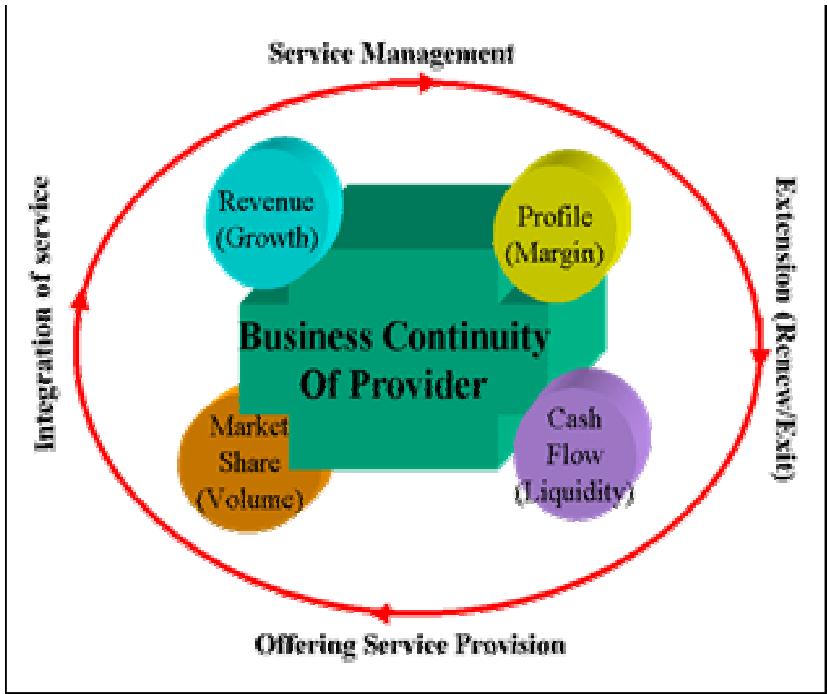

Figure 4: The Utility Business Services financial ess to ensure that they effectively communicate their needs, select the right source, negotiate a successful contracts, and obtain quality products and services" (Garrett 1997).

[b] Economic risks, looks into all financial aspects of the transaction including the financial health of the prospective service provider, i.e., look into the capital structure of the provider (equity and debit), their liquidity and credit status and, finally what has been annually reported in terms of their annual accounting. A client organization should also run a similar financial check on how its activities may be affected by adopting a service provision.

The knowledge-base framework looks into risks associated to the [1] offering process prior to the outsourcing contract being signed and the establishment of the service level agreement and its posterior and continuous monitoring and management (Figure 4); [2] to the integration of service to the business and technical structure as they are essential to synchronise client firm's processes. A successful service management demonstrating customer retention and business expansion, no breach of security and speed and professional problem resolution can lead to the extension and renew of the service. Both, supply and client organisations need to assess and measure the risk of the service provision.

As part of the risk mitigation and measurement, a firm wishing to adopt service provision should be able to interpret the current position of prospective suppliers by assessing their performance indicators against industry standards to understand its level of excellence. In the service provision space "a firm is excellent only if it has"..."the ability to transform itself in response to change in its environment" and for that purpose it needs slack to invest in research and development (Chakravarthy 1995).

If service provider organisations establish performance indicators that are based on benchmarks from the outsourcing/Utility/ASP industry, then those enterprises will have better chance of succeeding. The ability to generate and monitor performance indicators is synonym to the ability to provide good service levels. Whilst the barriers to entry for the service provision industry are low, the ability to gain competitive sustainability is complex and requires support from performance ma nagement.

[c] Information generation and management form another key set of risks. This is related to the production of information into and across the organization involved in the utility business service partnership but mostly concentrates on the data of the client organisation. It looks into systems and processes, their technology and it is concerned with the management of the information produced by these systems and processes, intellectual property and the assurance of ownership of the information produced. 
The issue of upgrading mission-critical applications may be more pervasive. When upgrading a software application, the ASP needs to perform extensive tests to ensure that all instances have been covered. This ultimately could prove very costly and inefficient for the ASP to undertake due to the specific business knowledge required. The ASP must follow formal methods to carry out software application upgrades, which need to be thoroughly tested for user acceptance prior to being released to client organisations. (See Figure 5.)

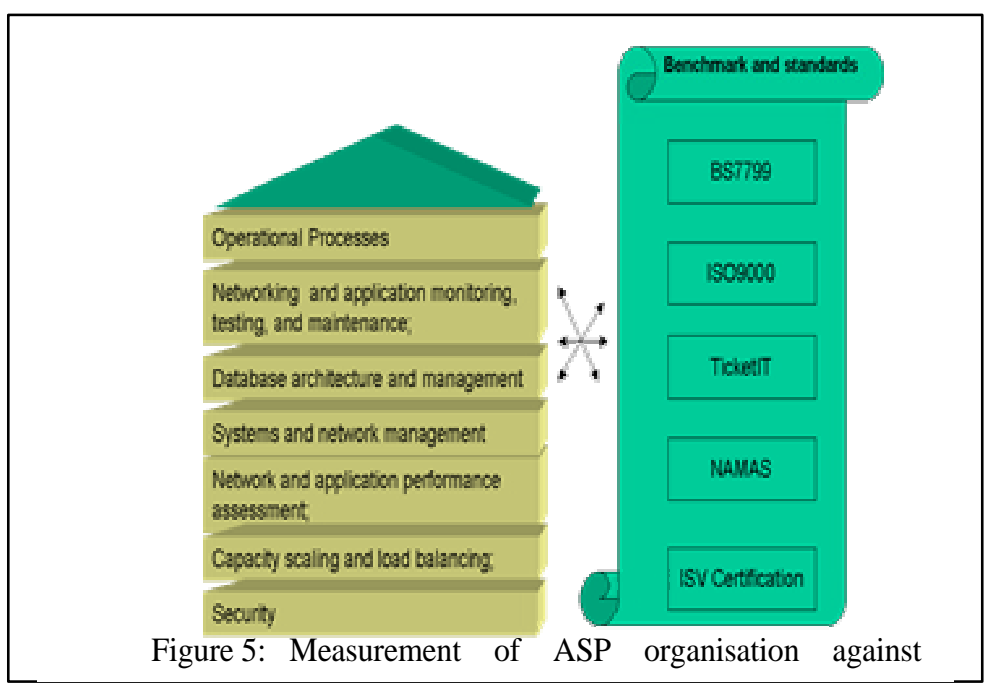

Equally, the contract will require clauses

for any technological and business changes. An understanding of the certification held by a service provider, is vital for the successful procurement of service provision. Certification offers the customer, some initial guarantee as to the standards and the quality of the organisation, its operations and its products.

For example; Cisco and Microsoft offer certification for ASP organisations providing their products. The British Institute of Standards offer the BS779 standard, which ensures compliance of business processes and procedures of an organization. The European version of the BS7799 is the ISO9000. There are also levels of certification using benchmarking such as service level agreements (SLAs). Certification also can assist to fill in the lack of marketing activity and material (Kern, Willcocks and Lacity 2002).

[d] Service and Delivery risks look into the internal organization of the supplier and customer, to understand which issues may surface from the way the supplier operates its business and how it may impact the client. It is interested in the physical assets, people and culture of the supplier as it is concerned on the effect the service will have over the client organization. Equally important is the processes trough that the provider manages its operation covering since marketing and selling, product delivery, support to services to client and research and deve lopment.

A vendor may not provide the desired level of operational or regulatory performance, which can impact the effectiveness of the client organization. This risk can be counter acted through formal contracts and service level agreements as well as rigorous measurement and analysis of user feedback (Garrett 1997).

Not all service and delivery risks are related directly to the service supplier. The client organization needs to integrate the external service to internal processes and procedures. This may involve the analysis of the areas of project planning systems; resource management systems, accounting and billing systems, asset utilization systems and performance measurement and reporting systems.

Another common area of concern is related to the legal issues of the data from the client organization being illegally accessed and used by the service provider staff. The contract should disclose what type of data manipulation is expected from and what would be regarded as an "illegal activity". Furthermore, the service provider organization not only needs to be responsible for the acts of its staff but also needs to maintain their skills, competences and capabilities commensurable to the service level agreed.

\section{Implementing the Risk Analysis}

Following identification of the risks, the next step is the prioritising of their impact over the project objectives. For the cases requiring gauging risk probability, then quantitative analysis should be carried 
out. Otherwise a response plan can be undertaken. The implementation of the risk analysis includes a risk response plan followed by a risk monitoring and control (Levin 2000, Wideman 1992).

The risk response plan seeks to assist the mitigation of risks by identifying and enhancing opportunities offered in risky situations. The establishment of a risk response plan for each identified risk includes (1) avoidance, (2) transference, (3) mitigation and (4) acceptance. The risk response plan should identify the specific owner for the risk, including residual risks and any secondary risks, the responsibilities and results from the analysis processes and also a budget and timetable for the response and contingency and fallback.

To complete the cycle of risk management, the next logical step is risk monitoring and control encompassing of a number of reports such as issues logs, action item lists, threat warnings or escalation notices.

In a very mature environment, the risk monitoring and control includes risk audits, risk reviews, earned value, technical performance measurement and additional response planning tools and techniques. A repository for collecting, maintaining and analysing the data gathered is also recommended. Following this initial step of accessing qualitative risks, the next stage is to examine the work required for the procurement, contract and management of the service.

\section{Summary and Outline of Future Research}

The research undertaken highlights the early analysis of the service provision business model (CherryTree\&Co 2000a) in which prior concerns were discussed and surveyed with vendor and customers (CSSA 2001, FEI, DTI, Afdec and SBA 2002) and is summarised in three main areas:

(a) Compatibility of software to the web environment and innovative capability of the software developer appeared to be a sensible concern from the customer risk analysis, as they want to ensure that their competitive position is not jeopardised by loosing sustainability due to poor information services. Through the CSSA surveys was detected that service provision firms were investing in technology development to refine the model rather than in marketing.

(b) Business and system integration is a key issue. This relates to the scope and flexibility of the services to be integrated with front and back-end applications of the customer. This is in itself, an extremely controversial issue, because within the 'purist' definition of ASP, there is the principle that the provision of service is one-to-many. In which case, the systems and their integration into the business should be very generic. However, many ASP providers and customers are working in a "many-to many" relationship, which defies the assumption of using an ASP to reduce costs, because the "one-tomany" leverage required to succeed in the long term. "One-to-one" relationship is considered uneconomical by ASP firms. Though for other services, it is feasible and economical to provide customisation, therefore amenable to a generic utility business service model.

(c) Vendor and customer need to state at the initial agreement the expected levels of service, quality of service and support expected. There should be a common agreement with regards availability, scalability, bandwidth, capacity, security, data and network management.

These results and other issues are important benchmarking factors, to ensure the sustainability of the utility business service model. In the field of innovation, "planning and serendipity can both be important and be intertwined" (Pearson 1992) yet uncertainty can be reduced by knowledge-based risk management processes increasing the performance and acceptability of the utility business service model, therefore contrib uting to its evolution. 


\section{References}

ALTERNATIVE, P. (2001). ALTERNATIVE Project (IST-2000-28421), Assessing the deployment, hosting and integration of business-critical information systems by Application Service Providers, Information Societies Research Group, School of Management, University of Surrey, www.alternative-Project.org/.

ASPConsortium. (2002). The Computing Technology Industry Association, www.comptia.org/sections/ssg/default.asp?refer=allaboutasp.

Avison, D. E. and Fitzgerald, G. (1991). Information systems practice; Education and research, Information Systems journal, 1,1 .

CherryTree\&Co. (1999). Application Service Providers (ASP), Spotlight Report, 15/11/2001, www.cherrytreeco.com.

CherryTree\&Co. (2000a). 2nd Generation ASPs, Spotlight Report, 15/11/2001, www.cherrytreeco.com.

CherryTree\&Co. (2000b). Pure-Play e-Business Development, Spotlight Report, 2001/10/03, www.cherrytreeco.com.

CSSA. (2001). Hardstats CSSA'S ASP Report; Computing Service and Software Association, www.cssa.co.uk.

Currie, W. (2000). Expanding IS Outsourcing Services Through Application Service Providers; Executive Publication Series CSIS2000/002.

Denzin, N. K. (1978). The Research Act: A Theoretical Introduction to Sociological Methods, McGraw-Hill,, New York.

Ernst\&Young. (2001). Risk Universe Framework. www.ey.com.

FEI, DTI, Afdec and SBA. (2002). A Study of the adoption of e-commerce by the, Federation of the Electronic Industry (FEI), Department of Trade and Industry (DTI), Afdec,Association of Franchised Distributors of Electronic Comp onents (Afdec), Semiconductor Businesses Association Electronics Scotland (SBA); Computing Service and Software Association, www.cssa.co.uk.

Garrett, G. A. (1997). World-Class Contracting, ESI International, Virginia.

Kern, T., Willcocks, L. P. and Lacity, M. C. (2002). Application Service Provision: Risk Assessment and Mitigation; MIS Quarterly Executive Vol. 1 No. 2 / June 2002, 1, 2.

Levin, G. (2000). Risk Management and the PMBOK® 2000 Edition.

Wideman, R. M. (1992.) Risk Management, A guide to Managing Project Risks \& Opportunities, Project Management Institute, Library of Congress Cataloging-in-Publication Data, Pennsylvania, USA.

\section{Biography}

Christina Silveira, MBA, MBCS, is an IT/IS consultant with more than 20 years of experience. Currently she is working at the ALTERNATIVE Project at the University of Surrey as Researcher Officer. She is also involved in a post-doctoral degree researching electronic business models and their infrastructure requirement. 